\title{
Canadian Thoracic Society COPD Guidelines: Summary of highlights for family doctors
}

\author{
Denis E O’Donnell MD* ${ }^{*}$, , Paul Hernandez $\mathrm{MD}^{\dagger, \ddagger}$, Shawn Aaron $\mathrm{MD}^{\ddagger}$, Jean Bourbeau $\mathrm{MD}^{\ddagger}$, \\ Darcy Marciniuk $\mathrm{MD}^{\ddagger}$, Rick Hodder $\mathrm{MD}^{\ddagger}$, Meyer Balter MD, Gordon Ford MD, Andre Gervais MD, \\ Roger Goldstein MD, Francois Maltais MD, Jeremy Road MD, Valoree McKay ${ }^{\S}$, Jennifer Schenkel ${ }^{\S}$ \\ *Chair, CTS COPD Guideline Development Committee; ${ }^{+}$Chair, CTS Implementation/Dissemination Committee; \\ ${ }^{\ddagger}$ Editorial Committee; ${ }^{\S}$ Canadian Lung Association Administrative Staff
}

\begin{abstract}
Chronic obstructive pulmonary disease (COPD) is a major cause of disability and death throughout the world. The main goal of this educational initiative of the Canadian Thoracic Society (CTS) is to optimize early diagnosis, prevention and management of COPD in Canada.
\end{abstract}

\section{Epidemiology}

Affecting about $4 \%$ of Canadian adults, COPD is a major health and economic concern. In 1999, COPD was the fourth leading cause of death in men and the fifth in women. It is predicted that morbidity and mortality from COPD will escalate over the next 15 years, particularly in the aging female population.

Key Message \#1: COPD is a respiratory disorder largely caused by smoking that is characterized by progressive, partially reversible airway obstruction, systemic manifestations, and increasing frequency and severity of exacerbations. Systemic effects include peripheral muscle dysfunction, right heart failure, polycythemia, change in nutritional status and depression, and these together with respiratory impairment contribute to a poor quality of life.

Key Message \#2: Family physicians have a primary role in the management of COPD. As primary health care providers, family physicians are responsible and ideally suited to provide early identification and diagnosis of COPD, patient education, smoking cessation counselling, initiation of drug treatment, management of acute exacerbations, long term follow-up and supportive end-of-life care.

Key Message \#3: Objective demonstration of air flow obstruction by spirometry is essential for the diagnosis of COPD. A postbronchodila-

\begin{tabular}{|l} 
Assessing Disability in COPD \\
\hline Grade $1 \rightarrow$ Breathless with strenuous exercise \\
Grade $2 \rightarrow$ Short of breath when hurrying on \\
the level or walking up a slight hill \\
Grade $3 \rightarrow$ Walks slower than people of the same \\
age on the level or stops for breath \\
while walking at own pace on the level \\
Grade $4 \rightarrow \begin{array}{l}\text { Stops for breath after walking } 100 \text { yards } \\
\text { Grade } 5 \rightarrow\end{array}$ \\
Too breathless to leave the house or \\
breathless when dressing
\end{tabular}

Figure 1) Medical Research Council dyspnea scale. COPD Chronic obstructive pulmonary disease. Data from reference 1 tor forced expiratory volume in $1 \mathrm{~s}\left(\mathrm{FEV}_{1}\right)$ of less than $80 \%$ of the predicted normal value and a ratio of $\mathrm{FEV}_{1}$ to forced vital capacity of less than 0.70 are both required for COPD to be diagnosed.

Key Message \#4: Most patients with COPD are not diagnosed until the disease is well advanced. Spirometry targeted at individuals who are at risk for COPD can establish an early diagnosis. The following criteria are helpful to family physicians when deciding who to target in their practice to undergo spirometry testing to detect COPD:

1. Smokers or exsmokers 40 years of age and older

2. Individuals with persistent cough and sputum production

3. Individuals with frequent respiratory tract infections

4. Individuals with progressive activity-related shortness of breath

\section{EVALUATION OF THE COPD PATIENT}

The patient's history should include number of pack-years of smoking, frequency and severity of exacerbations, and an assessment of dyspnea and disability.

Key Message \#5: The Medical Research Council dyspnea scale (Figure 1) is a functional scale that is useful to assess shortness of breath and disability, and can assist in the evaluation of disease severity (Table 1). Physical examination and chest $\mathrm{x}$-rays are not usu-

\section{TABLE 1}

Canadian Thoracic Society chronic obstructive pulmonary disease (COPD) classification by symptoms/disability*

\begin{tabular}{|c|c|}
\hline COPD stage & Symptoms \\
\hline $\begin{array}{l}\text { At risk (does not } \\
\text { 'yet' fulfill the } \\
\text { diagnosis of COPD) }\end{array}$ & $\begin{array}{l}\text { Asymptomatic smoker, exsmoker or chronic cough/ } \\
\text { sputum, but postbronchodilator } F E V_{1} / F V C \geq 0.7 \\
\text { and/or } \mathrm{FEV}_{1} \geq 80 \% \text { predicted }\end{array}$ \\
\hline Mild & $\begin{array}{l}\text { Shortness of breath from } \mathrm{COPD}^{\dagger} \text { when hurrying } \\
\text { on the level or walking up a slight hill } \\
\text { (MRC 2) }\end{array}$ \\
\hline Moderate & $\begin{array}{l}\text { Shortness of breath from COPD }{ }^{\dagger} \text { causing the patient } \\
\text { to walk slower than people of the same age on the } \\
\text { level or stop after walking about } 100 \mathrm{~m} \text { (or after a } \\
\text { few minutes) on the level (MRC 3-4) }\end{array}$ \\
\hline Severe & $\begin{array}{l}\text { Shortness of breath from COPD }{ }^{\dagger} \text { resulting in the } \\
\text { patient too breathless to leave the house, } \\
\text { or breathless after dressing/undressing (MRC 5), } \\
\text { or the presence of chronic respiratory failure } \\
\text { or clinical signs of right heart failure }\end{array}$ \\
\hline
\end{tabular}

*Postbronchodilator forced expiratory volume in $1 \mathrm{~s}\left(F E V_{1}\right) /$ forced vital capac ity (FVC) less than 0.7 and $F E V_{1}$ less than $80 \%$ predicted are both required for the diagnosis of COPD to be established; ${ }^{\dagger}$ In the presence of non-COPD conditions that may cause shortness of breath (eg, cardiac dysfunction, anemia, muscle weakness, metabolic disorders), symptoms may not appropriately reflect COPD disease severity. Classification of COPD severity should be undertaken with care in patients with comorbid diseases or other possible contributors to shortness of breath. MRC Medical Research Council 


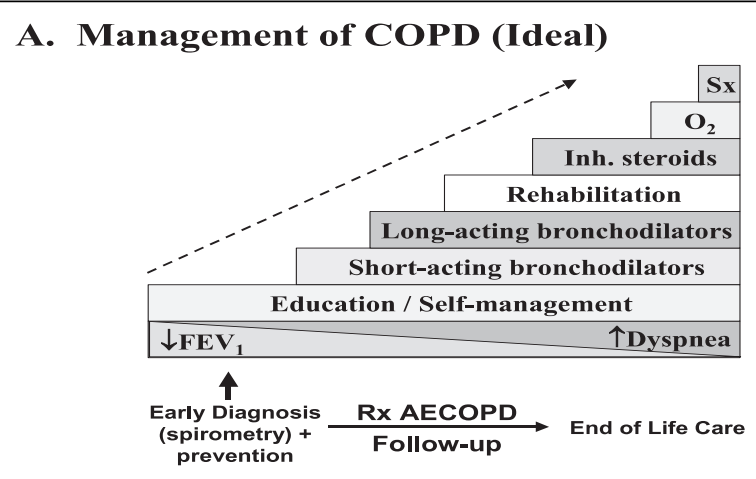

\section{B. Management of COPD (Current)}

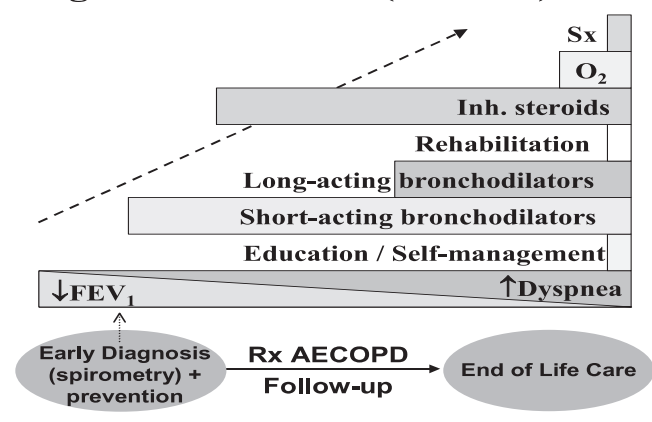

Figure 2) A Escalating management paradigm for chronic obstructive pulmonary disease (COPD) based on increasing symptoms and disability. B Current management deficiencies include lack of screening spirometry, education and rehabilitation, overuse of inhaled corticosteroids (Inh. steroids) in early disease and lack of structured end-of-life care. FEV $V_{1}$ Forced expiratory volume in $1 \mathrm{~s} ; \mathrm{O}_{2}$ Oxygen therapy; Rx AECOPD Treatment of acute exacerbations of COPD; Sx Lung volume reduction surgery or lung transplantation

ally diagnostic but are helpful to rule out comorbidities and complicating diseases. Arterial blood gases should be considered in patients with an $\mathrm{FEV}_{1}$ less than $40 \%$ predicted.

Key Message \#6: COPD and asthma are fundamentally different, and this diagnostic distinction should be made in each symptomatic patient. It may be difficult to differentiate COPD and asthma in some patients (eg, chronic asthmatic patients who smoke). COPD patients tend to have a later age of onset, a significant smoking history and slowly progressive symptoms over years. Patients with COPD never normalize their lung function. Blurring the distinction between asthma and COPD is not helpful, because it may lead to the inappropriate use of inhaled corticosteroids in patients with COPD or to the delayed use of inhaled corticosteroids in patients with asthma.

\section{Key Message \#7: Consider referral to a specialist when:}

1. Diagnosis is uncertain.

2. Symptoms are severe or disproportionate relative to the severity of air flow obstruction on spirometry.

3. Onset of symptoms is at a younger age (younger than 40 years).

Specialists can assist with the management of COPD patients who fail to respond to combined bronchodilator therapy, have severe or recurrent exacerbations, have complex comorbidities, require pulmonary rehabilitation, require assessment for home oxygen or may be candidates for surgical therapies (ie, lung transplantation, lung volume reduction surgery or bullectomy).

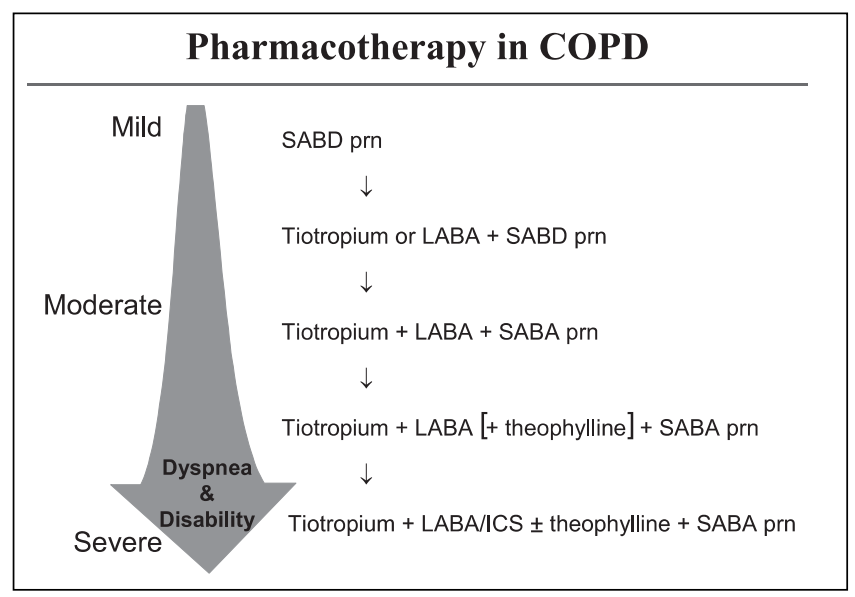

Figure 3) Pharmacological treatment of chronic obstructive pulmonary disease (COPD) based on increasing symptoms and disability. [+ theophylline] Add if tolerated; LABA Long-acting beta -agonist (ie, formoterol or salmeterol); LABA/ICS LABA combined with an inhaled corticosteroid in one preparation; SABA Short-acting betaagonist (ie, salbutamol); SABD Short-acting bronchodilator (beta ${ }_{2}$ agonists or anticholinergics)

\section{MANAGEMENT OF COPD}

Key Message \#8: COPD is amenable to therapy. A management strategy consisting of combined pharmacotherapy and nonpharmacotherapeutic interventions can effectively improve symptoms, activity levels and quality of life, even in patients with severe COPD. The goals of COPD management include preventing disease progression, alleviating symptoms, improving exercise tolerance, preventing and treating exacerbations, and reducing mortality. This requires a stepwise approach in which therapy is escalated based on the severity of symptoms and disability (Figure 2).

Key Message \#9: Smoking cessation is the single most effective intervention to reduce the risk of developing COPD and the only intervention that has been shown to slow its progression. At least $70 \%$ of smokers visit a physician each year, and advice from a physician is quoted as an important motivator to quit. Even brief counselling lasting less than 3 min should be offered to every smoker, with the understanding that more intensive therapy (individual and group counselling, nicotine replacement and the antidepressant bupropion), which results in in the highest quitting rates, should be used whenever possible.

Key Message \#10: Education of the patient and family with supervision and support based on disease-specific self-management principles is valuable. In addition to improving coping skills and quality of life, self-management plans also reduce hospitalization and health care costs. Collaboration among the patient, family and appropriately trained COPD educators is pivotal to success of education and selfmanagement plans.

Key Message \#11: Vaccinations prevent exacerbations of COPD. COPD patients infected with influenza are at higher risk for hospitalization, so an annual influenza vaccine is recommended. The benefit of pneumococcal vaccine is less well established, but we recommend that COPD patients be given this vaccine at least once, and possibly every five to 10 years.

Key Message \#12: Bronchodilators are the mainstay of COPD pharmacotherapy. They can reduce air trapping (lung overinflation) and dyspnea, and improve quality of life even if there is no improvement in spirometry (Figure 3). 
TABLE 2

Antibiotic treatment recommendations for purulent acute exacerbations of chronic obstructive pulmonary disease (COPD)

\begin{tabular}{|c|c|c|c|c|c|}
\hline Group & $\begin{array}{c}\text { Basic } \\
\text { clinical state }\end{array}$ & Symptoms and risk factors & Probable pathogens & First choice & $\begin{array}{l}\text { Alternatives for } \\
\text { treatment failure }\end{array}$ \\
\hline Simple & $\begin{array}{l}\text { COPD without } \\
\text { risk factors }\end{array}$ & $\begin{array}{l}\text { Increased cough and sputum, } \\
\text { sputum purulence and } \\
\text { increased dyspnea }\end{array}$ & $\begin{array}{l}\text { Haemophilus influenzae, } \\
\text { Haemophilus species, } \\
\text { Moraxella catarrhalis, } \\
\text { Streptococcus pneumoniae }\end{array}$ & $\begin{array}{l}\text { Amoxicillin, doxycycline, trimethoprim/ } \\
\text { sulfamethoxazole, second- or third- } \\
\text { generation cephalosporins, extended } \\
\text { spectrum macrolides }\end{array}$ & $\begin{array}{l}\text { Beta-lactam/ } \\
\text { beta-lactamase } \\
\text { inhibitor; } \\
\text { fluoroquinolone }\end{array}$ \\
\hline Complicated & $\begin{array}{l}\text { COPD with } \\
\text { risk factors }\end{array}$ & $\begin{array}{l}\text { As in simple plus at least one of: } \\
\cdot \mathrm{FEV}_{1}<50 \% \text { predicted } \\
\cdot \geq 4 \text { exacerbations/year } \\
\text { - Ischemic heart disease } \\
\text { - Use of home oxygen } \\
\text { - Chronic oral steroid use } \\
\text { - Antibiotic use in the previous } 3\end{array}$ & $\begin{array}{l}\text { As in class I plus } \\
\text { - Klebsiella species plus } \\
\text { other Gram-negatives } \\
\text { - Increased probability } \\
\text { of beta-lactam resistance } \\
\text { onths }\end{array}$ & $\begin{array}{l}\text { Beta-lactam/beta-lactamase inhibitor; } \\
\text { fluoroquinolone } \\
\text { (antibiotics for uncomplicated } \\
\text { patients when combined with oral } \\
\text { steroids may suffice) }\end{array}$ & $\begin{array}{l}\text { May require } \\
\text { parenteral } \\
\text { therapy; consider } \\
\text { referral to a } \\
\text { specialist or } \\
\text { hospital }\end{array}$ \\
\hline
\end{tabular}

FEV 1 Forced expiratory volume in $1 \mathrm{~s}$

- For patients with activity-related breathlessness and minimal disability, initial treatment should be with a short-acting beta agonist as needed (or a regular anticholinergic or combination anticholinergic/beta 2 -agonist). The choice of first-line therapy is based on clinical response and tolerance of adverse effects.

- If symptoms persist despite this, add a long-acting bronchodilator such as an anticholinergic (tiotropium $18 \mu \mathrm{g} q \mathrm{~d}$ ) or a long-acting beta $_{2}$-agonist (LABA) (formoterol $12 \mu \mathrm{g}$ bid or salmeterol $50 \mu \mathrm{g}$ bid) should be added. Continue a short-acting bronchodilator as needed for immediate symptom relief.

- For patients with moderate to severe persistent symptoms, a combination of a long-acting anticholinergic and an LABA is recommended in addition to an as-needed short-acting beta $_{2}$-agonist for immediate symptom relief.

- In patients with severe symptoms despite the use of both a long-acting anticholinergic and an LABA, a long-acting oral theophylline may be tried. Monitoring of theophylline blood levels for adverse effects and for drug interactions is necessary.

- Long term maintenance treatment with oral corticosteroids has no proven benefit in COPD and is associated with a high risk of serious adverse effects.

- Unlike asthma, inhaled corticosteroids (ICSs) should not be used as a first-line medication in COPD. However, ICSs should be considered in patients with moderate to severe COPD who experience three or more acute exacerbations per year, especially if these exacerbations require treatment with oral steroids.

- Patients who remain breathless despite optimal bronchodilator therapy may benefit from the addition of a combination of ICS/LABA, but this should be considered on an individual basis.

Key Message \#13: All COPD patients should be encouraged to maintain an active lifestyle. COPD patients with activity-related shortness of breath tend to reduce activity levels to avoid precipitating respiratory discomfort. Deconditioning due to inactivity contributes to generalized skeletal muscle dysfunction so that even minor activity provokes limb fatigue. Clinically stable COPD patients who remain breathless and limited in their activity despite optimal bronchodilators should be referred to an exercise training program. Formal pulmonary rehabilitation programs that include supervised exercise training and patient education have been shown to consistently improve breathlessness, exercise endurance and quality of life, and may reduce emergency visits and hospitalizations in patients with COPD.

Key Message \#14: Acute exacerbations of COPD (AECOPD) are the most frequent cause of medical visits, hospitalizations and death among COPD patients. AECOPD is defined as a sustained worsen- ing of dyspnea, cough or sputum production leading to an increase in the use of maintenance medications and/or supplementation with additional medications. AECOPD is further classified as either purulent or nonpurulent. Antibiotics should only be considered in patients with purulent AECOPD. History, physical examination and chest $\mathrm{x}$-rays are recommended for patients with AECOPD. Sputum Gram stain and culture should be considered for patients with very poor lung function, those with frequent exacerbations or those who have been on antibiotics in the previous three months. Spirometry should be completed in patients suspected of having COPD only after recovery and when they are stable.

- Combination therapy with short-acting beta 2 -agonists and anticholinergic bronchodilators should be used to treat dyspnea in AECOPD. Patients already on an oral methylxanthine may continue this therapy during AECOPD, but there is no role for the new initiation of therapy.

- Oral or intravenous steroids should be administered for 14 days in most moderate to severe COPD patients with AECOPD; however, shorter treatment periods of between seven and 14 days may also be effective. Doses equivalent to 25 to $50 \mathrm{mg}$ of prednisone per day are recommended.

- Antibiotics are beneficial in severe AECOPD, which are episodes associated with increased dyspnea and increased sputum purulence or volume. Patients with simple AECOPD (Table 2) have no risk factors for treatment failure; relatively inexpensive antibiotics can target likely pathogens. Patients with complicated AECOPD have risk factors for treatment failure and/or infection with more virulent or resistant organisms. If a patient requires repeated antibiotic therapy within three months, a different class of antibiotics should be used to minimize the risk of resistance.

- In severe AECOPD complicated by acute respiratory failure not responsive to initial bronchodilator therapy, ventilatory support may be indicated and beneficial. Consultation with a COPD specialist is recommended in this setting.

Key Message \#15: COPD is a progressive, disabling condition that ultimately ends in respiratory failure and death. Physicians have a responsibility to provide support to COPD patients and their caregivers at the end of life.

Please refer to the Canadian Respiratory Journal, Volume 10, Supplement A, for the Executive Summary. The complete document of the CTS COPD Guidelines will be published at a later date.

\section{REFERENCE}

1. Fletcher CM, Elmes PC, Wood CH. The significance of respiratory symptoms and diagnosis of chronic bronchitis in a working population. Br Med J 1959;1:257-66. 


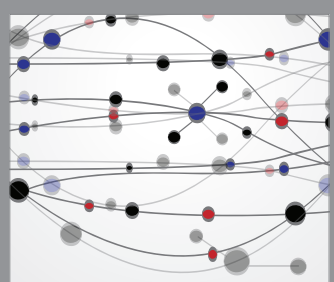

The Scientific World Journal
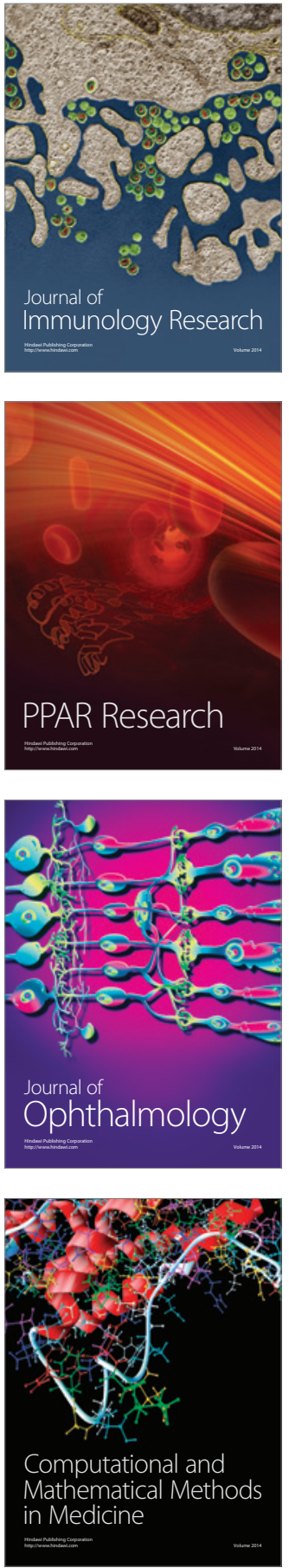

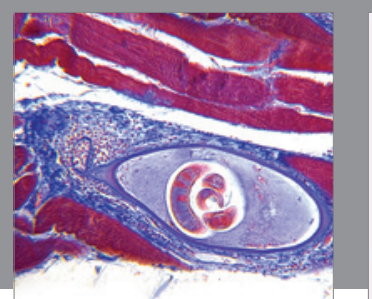

Gastroenterology Research and Practice

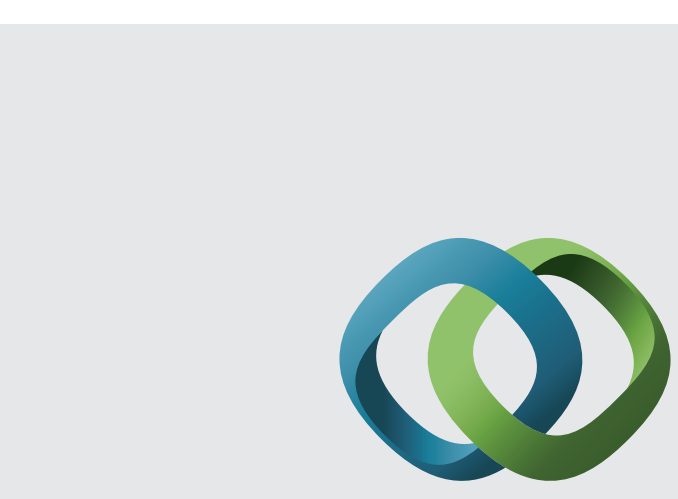

\section{Hindawi}

Submit your manuscripts at

http://www.hindawi.com
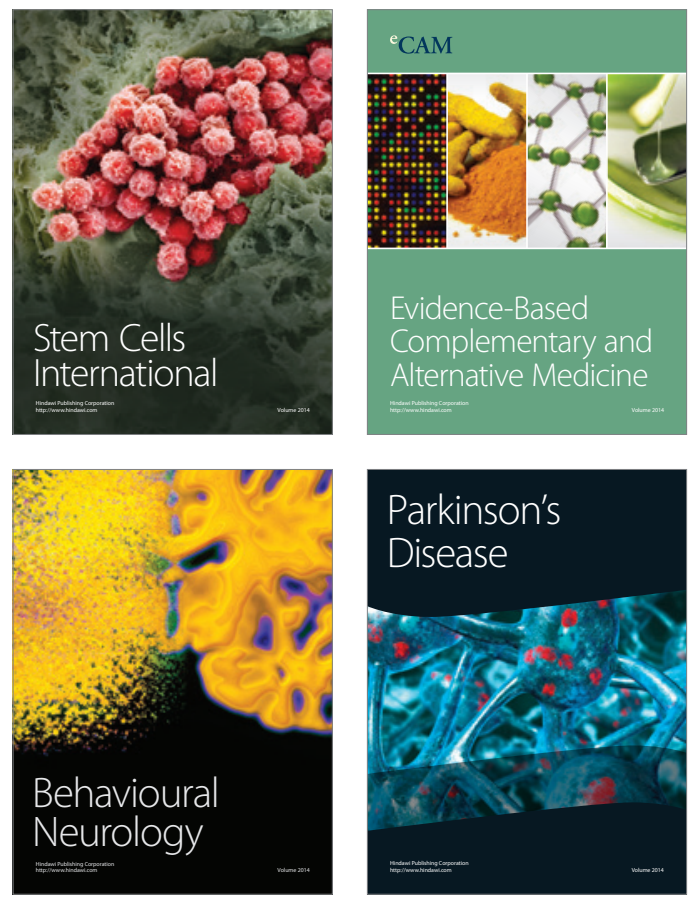
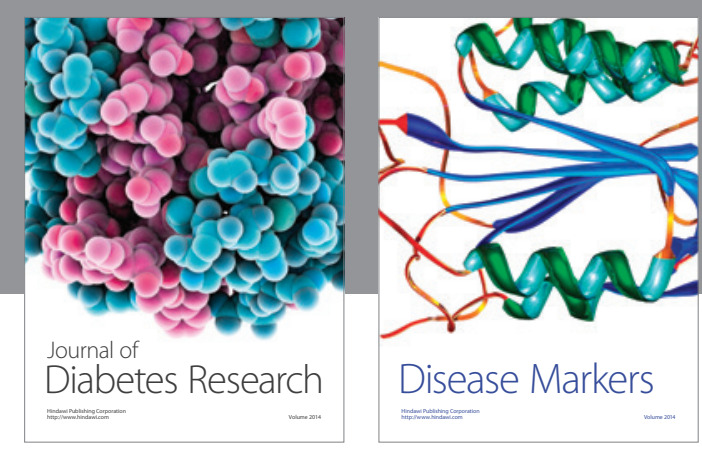

Disease Markers
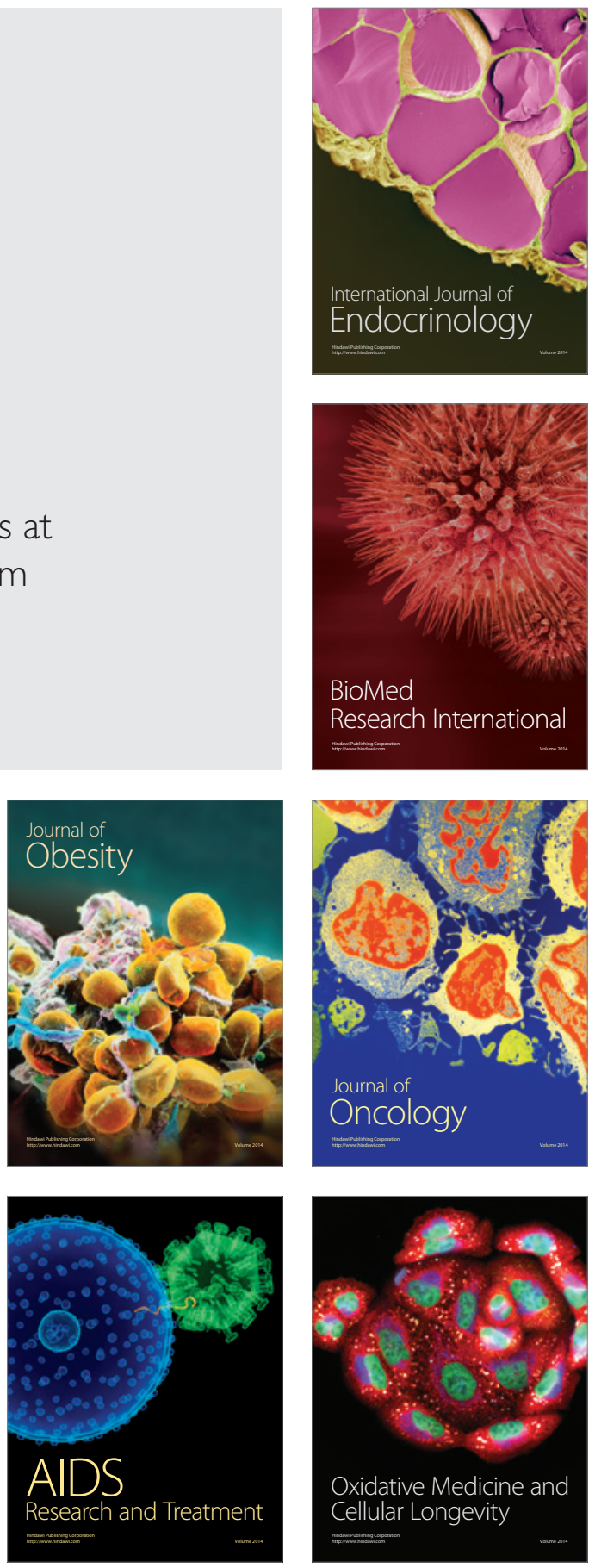